\title{
Necessary Moral Truths and Theistic Metaethics
}

\author{
By John Danaher
}

Forthcoming in SOPHIA DOI: 10.1007/ s11841-013-0390-0

\begin{abstract}
Theistic metaethics usually places one key restriction on the explanation of moral facts, namely: every moral fact must ultimately be explained by some fact about God. The problem is that the widely-held belief that some moral truths are necessary truths undermines this claim. If a moral truth is necessary, then it seems like it neither needs, nor has an explanation. Or so the objection typically goes. Recently, two proponents of theistic metaethics - William Lane Craig and Mark Murphy - have argued that this objection is flawed. They claim that even if a truth is necessary, it does not follow that it neither needs nor has an explanation. In this article, I challenge Craig and Murphy's reasoning on three main grounds. First, I argue that the counterexamples they use to undermine the necessary truth objection to theistic metaethics are flawed. While they may provide some support for the notion that necessary truths can be explained, they do not provide support for the notion that necessary moral truths can be explained. Second, I argue that the principles of explanation that Murphy and Craig use to support theistic metaethics are either question-begging (in the case of Murphy) or improperly motivated (in the case of Craig). And third, I provide a general defence of the claim that necessary moral truths neither need nor have an explanation.
\end{abstract}

Keywords: Metaethics; Necessary Truths; Theism; Explanation; William Lane Craig; Mark Murphy 


\section{Introduction}

For many theists, the notion that God grounds and explains moral truths is a key commitment. Murphy, for instance, has argued that the theistic programme in metaethics is centrally characterised by the claim that every moral fact is ultimately explained by some fact about God. ${ }^{1}$ And while the theistic programme is a broad church - encompassing the views of voluntarists, natural law theorists and concurrentists (like Murphy) - the commitment to the explanatory primacy of God seems to be shared by the majority of the congregation.

But there is a problem with this commitment. The widespread view that moral truths such as pain is intrinsically bad or torturing innocent children for fun is impermissible are necessary seems to undermine it. ${ }^{2}$ The objection runs as follows: if a truth is necessary, then it either does not need or does not have an explanation; this is incompatible with the central commitment of theistic metaethics; therefore, something has to give and that something should be the commitment of theistic metaethics, presumably because it is less secure than the belief that necessary truths neither need nor have explanations. We can call this the "necessary-truth objection".

As attractive as this objection first seems, it has been challenged by some proponents of the theistic programme. This article looks at two such challenges. ${ }^{3}$ The first, coming from the work of William Lane Craig, and the second, from the work of Mark Murphy. Both authors adopt a similar argumentative strategy, identifying a number of counterexamples to the claim that necessary truths neither need nor have

\footnotetext{
${ }^{1}$ See Murphy, M. God and Moral Law (Oxford: OUP, 2011), chapter 2. Murphy adds that the explanatory role played by God must be direct, not indirect. See Murphy, 2.4 on this latter point.

${ }^{2}$ I use these two examples throughout the article, partly because they are used by Murphy, but also partly because they cover axiological and deontological moral facts. Some proponents of theistic metaethics, particularly modified Divine Command Theorists, might concede an axiological version of the necessary truth objection, but dig in their heels at the deontological version. The suggestion made throughout this article is that both species of moral fact share the same features and hence any successful version of the necessary truth objection should cover both.

${ }^{3}$ Others have made arguments and developed theories that could be relevant to the necessary-truth objection. See, for example, Plantinga, A. "Naturalism, Theism, Obligation and Supervenience" (2010) 27 Faith and Philosophy 247 272 , which considers explanatory asymmetry among necessary truths (though the immediate target in that article is naturalism, not moral realism, the latter being the only view I presuppose in this article); and Morris, T. \& Menzel, C. “Absolute Creation" (1986) 23 American Philosophical Quarterly 353-362, who try to resolve the tension between theism and Platonism. There are many others too who address the relationship between Platonism and Theism. I focus on Craig and Murphy because they directly engage with the necessary-truth objection to theistic metaethics, and adopt similar argumentative strategies. A complete defence of the necessary-truth objection would require me to engage with other views too, but is beyond the scope of this one article. Here, I merely aim to defuse one set of challenges, and offer a partial defence of the objection.
} 
explanations, and using these counterexamples as a springboard to formulate principles of explanation that allow for necessary moral truths to be explained.

In this paper, I will argue that the challenges mounted by Craig and Murphy are flawed. My argument shall proceed in four parts. First, I will try to clarify the nature of the necessary-truth objection, pointing out the importance of distinguishing between its two different forms. These I call the no-explanation-needed (NEN) form and the noexplanation-possible (NEP) form. I will argue that it is best to interpret the necessarytruth objection in the NEP form, not in the NEN form (though participants in this debate are not always consistent on this matter). Second, I will discuss Craig's response to the NEP argument, highlighting the flaws in the counterexamples he uses to support his response and the alternative principle of explanation to which he appeals. Third, I will do the same for Murphy's response to the NEP argument. And fourth, I will conclude by presenting a partial general defence of the NEP argument.

\section{The NEP and NEN Arguments}

The necessary-truth objection claims that necessary truths either do not need, or do not have explanations. But which is it? Is it that they do not need explanations, or is it that they do not have them? Does this distinction make any difference? In this section, I argue that it does.

\section{1 - Explaining Moral Facts}

To support this argument, some conceptual clarification needs to take place. In particular, there is a need to clarify the kinds of fact we are trying to explain, and the motivations behind our quest for an explanation. Only after we clarify these points will we be able to determine the significance of the need/have distinction.

So let us turn to the first issue. What kinds of fact are we trying to explain? A fact, for present purposes, will be defined as any actually existent entity, event or state of 
affairs. ${ }^{4}$ Generally speaking, there are two types of moral status we can attach to a fact: (i) a value status, i.e. we can say that the fact is "good" or "bad"; or (ii) a deontic status, i.e. we can say that the fact is obligatory, permissible, or forbidden (under some systems of deontic logic, additional deontic statuses are possible). In this particular context, it is the attachment of moral statuses to entities, events and states of affairs that we are trying to explain. In other words, we are not trying to explain any particular moral fact per se (although examples will be used throughout), but, rather, the more general fact that moral statuses attach to facts.

This is not all we are trying to do. We are specifically concerned with moral statuses that are necessary. There are many things one could mean by saying that a moral status is "necessary", so it is important to be clear which meaning is intended. ${ }^{5}$ In this article, all references to the notion of a moral status being necessary are intended to denote a logically/analytically necessary fact ${ }^{6}$ or, more commonly, a metaphysically necessary fact. I here adopt the standard possible-worlds analysis of both kinds of necessity. ${ }^{7}$ According to this analysis, a fact can be deemed logically or metaphysically necessary if it is true in all possible worlds. That is, if there is something in the nature or structure of the fact which mandates its truth across all possible worlds. Since it will become useful later, it is worth distinguishing this logical/metaphysical brand of necessity from another type of necessity, one we might call factual necessity. ${ }^{8}$ Something is factually necessary whenever there are possible worlds in which it could fail to exist but in whichever worlds it does exist it cannot fail to exist. Thus, a factually necessary being is a being that cannot cease to exist in one particular world, and a

\footnotetext{
${ }^{4}$ Cf. Murphy (2011) on moral facts, pg 46, where he describes moral facts as any facts that fit the general pattern "A is morally required to X" or "A's X-ing is the morally right thing to do" and so forth.

${ }^{5}$ The concept of necessity, particularly when applied to discussions of God and morality, begets a surprisingly large number of variants. For a discussion of necessity as applied to God, see Philipse, H. God in the Age of Science? a Critique of Religious Reason (Oxford: OUP, 2012), chapter 8. For a discussion of moral necessity, see Murphy (2011) pp. 36-37. There, Murphy argues that moral necessity is a species of practical necessity such that " $\mathrm{X}$ is morally necessary" means roughly that "there are decisive normative reasons in favour of X." Murphy is clear later in the text (p. 47) that there is a distinction between this notion of moral necessity, and the fact that certain moral necessities are necessarily obtaining states of affairs. The latter has to do with whether there are decisive normative reasons across all possible worlds and it is this feature of certain moral facts that I am concerned with in this article. Thus, nothing I say here is inconsistent with the notion of there being distinct concept of moral necessity.

${ }^{6}$ This is to capture Swinburne's conceptualisation of necessary moral facts. I don't wish to pass any judgment on this conceptualisation here, but for a critical discussion see: Rahimi, S. "Swinburne on the Euthyphro Dilemma: Can Supervenience Save Him?” (2008) 13 Forum Philosophicum 17-29

${ }^{7}$ Essentialist or conventionalist analyses have also been invoked. See Cameron, R. "The Grounds of Necessity" (2010) 5 Philosophy Compass 348-358

${ }^{8}$ I would like to thank Dr. Felipe Leon for bringing the distinction and the labels to my attention.
} 
factually necessary proposition is one that cannot fail to be true in a particular world. As I say, the distinction counts for little right now, but becomes significant later when we analyse some of Craig and Murphy's arguments.

For the time being our focus remains on the notion of logical or metaphysical necessities. There are many facts that might be logically or metaphysically ${ }^{9}$ necessary: mathematical facts, of the type " $2+2=4$ ", might be necessary; theistic facts - facts about God's nature and being — might be necessary since God is classically defined as a necessary being; and some moral facts, such as "pain is intrinsically bad" or "it is forbidden to torture children for fun" might be necessary. ${ }^{10}$ The use of the qualifier "might" is important here. With the exception of mathematical and logical truths, there is plenty of room for disagreement about which kinds of fact are truly necessary. I take no view on these disagreements here. For the sake of argument, I will simply assume that there are at least some necessary moral facts, and pursue the issue of whether these necessary moral facts need or have an explanation.

This brings us to the second issue. What exactly motivates the search for an explanation of moral facts? Lipton tells us that there are both instrumental and intrinsic goods that motivate our search for explanations. ${ }^{11}$ The instrumental goods vary from person to person. For example, I may wish to find a non-theistic explanation for moral facts simply because I wish to score debate points against a theistic opponent. That would be a somewhat shallow and uninteresting good and, in any event, my ability to satisfy it would ultimately be dependent upon the intrinsic good of the explanation, the good that attaches to every explanation irrespective of individual desires. This intrinsic

\footnotetext{
${ }^{9}$ I will drop this qualification from now on and refer simply to "necessary" facts once more, until I reintroduce the notion of factual necessity in a later section.

${ }^{10} \mathrm{An}$ anonymous reviewer worried that the arguments throughout did not adequately address the possibility that truths of this sort were merely conceptually true not metaphysically true - i.e. they were just part of a language game that doesn't reflect or track reality. The worry being that in failing to address this I was assuming the substantive truth of what needed to be the case for my arguments to succeed (namely: that there are metaphysically necessary moral truths). Three responses occur to me here. First, as I say in the text, I am indeed assuming that there are metaphysically necessary truths of this sort, for the sake of argument. I am willing to accept that this could be wrong, but since it looks to be a view shared by the critics with whom I am engaging, it seems like a justifiable assumption. Second, I think the examples used throughout this article have a serious whiff of metaphysicality about them since they directly target or pick out entities and states of affairs in the real world, certainly more so than, say, Aquinas's classic injunction to "do good, avoid evil", which I think is a wholly conceptual truth. And third, I am not sure that conceptual truths of this sort raise analogous problems for theistic or non-theistic metaethics.

11 "What Good is an Explanation?" in Cornwall, J. Understanding Explanation (Oxford: Oxford University Press, 2004)
} 
good is the common attractor point that renders an explanation worthwhile and capable of scoring debate points in the first place.

The intrinsic good of an explanation is usually cashed-out as the good of "understanding". The problem with this, as Lipton points out, is that there are several different conceptualisations of understanding to which we may appeal. ${ }^{12}$ Fortunately, these divide into two general categories: epistemic conceptualisations ; and ontological conceptualisations. An epistemic conceptualisation links explanations to our epistemic needs. Under this view, our goal in explaining a fact is to satisfy curiosity, to provide reasons for belief, to render the fact more familiar and so on. An ontological conceptualisation links explanations to the metaphysical structure of reality. Under this view, our goal in explaining a fact is to identify the other facts that caused it to be or that necessitated its existence. ${ }^{13}$ Another way of putting it is to say that an ontological conceptualisation focuses on the ontological grounding of facts, whereas an epistemological conceptualisation focuses on how the fact fits within our web of beliefs. Using this conceptual division of labour, we can distinguish between arguments claiming that a fact doesn't need an explanation, and arguments claiming that a fact doesn't have an explanation. The former set of arguments appeal to the epistemic functions of an explanation; whereas the latter appeal to the ontological functions of an explanation.

These functions may be linked in many cases. It may be that whenever we explain what ontologically grounds some fact we thereby satisfy our epistemic needs. Arguably, this is what should happen. But it may also be the case that the epistemic and ontological functions pull apart. ${ }^{14}$ Thus, there may be facts that do not need an explanation (epistemically speaking), but have explanations nevertheless (ontologically speaking) and vice versa. For instance, we might wish to explain why there was famine in a particular country and we might be offered the explanation that a famine was caused by a drought. This should satisfy our epistemic needs in this case. The further fact that there was a drought does not, in this context, need an explanation, even though

\footnotetext{
${ }^{12}$ By his count there are five: to find reasons for $\mathrm{X}$; to render $\mathrm{X}$ more familiar; to unify $\mathrm{X}$ with other aspects of our knowledge; to say what caused $\mathrm{X}$ to be; and to say why $\mathrm{X}$ was necessary. Lipton ibid

${ }^{13}$ Note: to necessitate a fact is not the same thing as to render that fact a necessary truth.

${ }^{14}$ Murphy, (2011) p. 45-46 argues that the epistemic function is parasitic upon the ontological function.
} 
it may, ontologically speaking, have one. Contrariwise, there may be explanations that we would really like to have, to satisfy our epistemic curiosity, but which will never be forthcoming because the facts in question do not have explanations. Maitzen ${ }^{15}$ has recently argued that the epistemic yearning for an answer to the primordial existential question $^{16}$-- why does anything exist? -- is of this sort. He alleges that this is because "anything" or "something" are dummy sortals, and so are not facts that are capable of being explained. We can yearn for an explanation all we like; one will never arrive.

\section{2 - Understanding the Necessary Truth Objection}

These distinctions are significant when it comes to addressing the precise nature of the necessary-truth objection to theistic metaethics. As noted in the introduction, the necessary-truth objection can sometimes blur the boundary between "need" and "have". This is unfortunate for at least two reasons. First, whether the objection is couched in terms of necessary truths needing or having an explanation can affect the strength of the objection. Secondly, the counterexamples and responses from the likes of Craig and Murphy may work well against one version of the objection and not the other. Thus, in what follows I will try to distinguish between the two versions of the objection and determine which should be the primary focus of our attention.

To do this, I need to identify the basic structure of the necessary-truth objection. I take it that the following argument captures this structure.

(1) If $X$ is a necessary truth, then $X$ does not need/have an explanation.

(2) Some moral truths are necessary truths.

(3) Therefore, some moral truths do not need/have an explanation (from 1 and 2).

(4) If there is to be a satisfactory theistic metaethics, then every moral fact either ultimately is/needs to be explained by some fact about God.

(5) Therefore, there can be no satisfactory theistic metaethics (from 3 and 4).

\footnotetext{
${ }^{15}$ Maitzen, S. "Stop Asking Why There's Anything” (2011) Erkenntis, DOI 10.1007/s10670-011-9312-0

${ }^{16}$ The term comes from Grunbaum, A. "The Poverty of Theistic Cosmology" (2004) 55 British Journal for the Philosophy of Science 561-614.
} 
The first premise currently contains the conflation of needing and having discussed above. This conflation (and its heritability by premises 3 and 4) will be removed once we refine it. Furthermore, as I said above, there are probably many reasons to doubt the truth of premise (2), but for the purposes of this article we are assuming its truth and seeing what follows.

Premise (4) is rather more problematic. It may be deemed excessive by some proponents of theistic metaethics. Is it really true, they may ask, that every moral fact must be explained by God? Three responses seem apposite. First, some proponents of theistic metaethics do indeed seem to think that this is true, and this includes the proponents whose views are being discussed in this article. ${ }^{17}$ Second, the addition of the word "ultimately" should be noted here: it may well be that God does not immediately explain some moral truths, but ultimately He must. This should not be too troubling to theists, who typically believe God is the ground of all being. ${ }^{18}$ And third, the concern here is with seemingly incontrovertible moral facts, which are presumably the moral facts with the greatest weight or significance. It seems likely that they, more than any others, would be the ones explained by God. Premise (4) could be reformulated to make this more restricted claim. So premise (4) should not worry us any further in this article.

With those observations out of the way, attention can be focussed on premise (1), where it will stay for the remainder of the article. This is what carries the argumentative burden and this is what Craig and Murphy wish to attack in their critiques. It is crucial that we understand it properly. In this regard, we must first distinguish between its "need" and "have" versions. As follows:

$\left(1^{*}\right)$ If $\mathrm{X}$ is a necessary truth, then $\mathrm{X}$ does not need an explanation (call this the "no explanation needed" principle, or the NEN principle for short).

$\left(1^{* *}\right)$ If $\mathrm{X}$ is a necessary truth, then $\mathrm{X}$ does not have an explanation (call this the "no explanation possible" principle, or the NEP principle for short).

\footnotetext{
${ }^{17}$ Murphy and Craig both seem to support this view

${ }^{18}$ Murphy (2011), chapter 1 makes this point when discussing explanans-centred criteria for explanation, as opposed to explananda-centred criteria.
} 
The NEN principle $\left(1^{*}\right)$ appeals to our epistemic needs, and the NEP principle ( $\left.1^{* *}\right)$ appeals to the ontological function of explanations. Two questions arise about these principles: (i) what justifies them? and (ii) how ought the necessary-truth objection be understood, i.e. does it work from the NEN or the NEP principle? I answer both questions in turn.

The NEN and NEP principles could be thought to derive their force from two related principles of explanation. The principles are as follows:

No Infinite Regress Principle (NIRP): We cannot ask for explanations of every fact; otherwise we would have an infinite regress of explanations. In other words, explanations must terminate somewhere, i.e. in some set of sui generis, basic, self-evidencing facts.

Counterfactual Principle (CP): Explanations show us how something that need not have been the case is the case. In other words, explanations show us how something that could have been otherwise is not as it otherwise could have been.

Both principles provide some support for NEN and NEP, although CP provides the most obvious support for both. CP states that explanations are relevant when dealing with contingent facts, i.e. facts that are not true in all possible worlds. Necessary facts, which by contrast are true in all possible worlds, are not contingent. So if CP is true, necessary facts will definitely neither need nor have explanations.

The situation with regards to NIRP is more complex. NIRP provides some support for NEN because it suggests that our epistemic need for explanations must terminate at some point. If we add the claim that necessary facts seem like an appropriate place to end the quest for understanding, then NEN is supported. But the problem is that it is not clear why necessary facts are the most appropriate point to end the quest. Perhaps we cannot, like children, ask "why X?" about everything, but we don't want to end the quest prematurely either. If some necessary facts have explanations, it would seem 
churlish to simply insist that we need not look for them. This is where NIRP support for NEP becomes significant. If necessary truths are sui generis, basic or self-evidencing, then we could be on firmer footing. We would then be provided with some reason for thinking that necessary truths are natural stopping-points on the train of explanation. But are necessary truths of this sort? Or, more precisely, are necessary moral truths of this sort? That is the question at the heart of this debate.

This brings us naturally to the next issue: how ought the necessary-truth objection be understood? The answer, I believe, is that it should be understood in terms of the NEP-principle, not the NEN-principle. If we understand the argument in terms of whether necessary moral facts need explanations - that is, in terms of whether our psychological makeup is such that we demand explanations in a particular context - we run the risk of prematurely denying ourselves access to otherwise valid explanations and expecting access to invalid ones. But if we understand it in terms of whether necessary moral facts have explanations, we make a stronger objection. For if necessary facts cannot have explanations, all attempts by theists to find them will be in vain. Complementing this observation, I think Craig and Murphy should, in the interests of interpretive charity, be understood as responding to the NEP version of the argument, unless this interpretation is directly contradicted by something they have said.

One important caveat to all this: epistemic or evidential criteria will still play an important part in deciding whether something falls afoul of the NEP principle. If something seems not to require an explanation, after suitable investigation and argumentation, this must be taken to provide some (defeasible) evidence for the claim that it does not have an explanation. This seems unavoidable since we cannot "get outside" our evidence and view the structure of metaphysical reality as it really is.

The clarification of the necessary-truth objection is now complete. In the next two sections I consider Craig and Murphy's responses to it. As we shall see, both authors initially attempt to undermine premise (1) by appealing to one or more counterexamples - i.e. situations in which necessary truths appear to actually have explanations - and by then attempting to substitute principles of explanation that do not support NEP. I will 
argue that their responses are flawed and then, in the final section, I will provide a general defence of NEP, or rather, a refined version of it that applies specifically to moral facts.

\section{William Lane Craig contra NEP}

William Lane Craig has written about the need for a theistic metaethics in innumerable venues over the years. ${ }^{19}$ In the course of so doing he has directly responded to the necessary-truth objection. I shall focus primarily (with some supplementation) on the response in the third edition of his book Reasonable Faith ${ }^{20}$ since the discussion there largely collates and replicates what he has said elsewhere on the topic.

\section{1 - Craig's Counterexamples}

Craig begins his response by identifying some counterexamples to NEP. In doing so he offers a modus tollens-style argument against NEP:

(6) If NEP were true, then no necessary facts would have explanations.

(7) $\mathrm{X}$ is a necessary fact.

(8) X is explained by $Y$.

(9) Therefore, NEP is false (from 6,7 and 8).

The key variables here are, of course, the necessary facts (Xs) and explanations (Ys) that Craig uses to flesh out this argument. Such X-Y pairs constitute a set of counterexamples to NEP. In Reasonable Faith, Craig uses three different X-Y pairs to make his case. ${ }^{21}$ In setting them up, he offers the general observation that it is possible for necessary truths to stand in relationships of explanatory priority to one another. So for Craig both the Xs and Ys in his examples are necessary facts - this is not

\footnotetext{
${ }^{19}$ Craig's output is vast but some examples of specific discussions of morality that I have relied on in this article include Craig "The Indispensability of Theological Metaethical Foundations for Morality" (1997) 5 Foundations 9 12 available at http://www.leaderu.com/offices/billcraig/docs/meta-eth.html (accessed 4/09/12); Reasonable Faith (3rd Edn, Crossway, 2008) pp. 172-183; Wallace, S. (ed) Does God Exist? The Craig-Flew Debate (Ashgate, 2003), pp. 168-172; and Garcia \& King (eds) Is Goodness without God Good Enough? (Rowman \& Littlefield, 2009), pp. $168-173$.

${ }^{20}$ (3rd Edn, Crossway, 2008)

${ }^{21}$ Craig (2008) p 178. A very similar set of counterexamples is presented in Craig (2003) p. 169.
} 
insignificant, as it happens, since it raises the spectre of an explanatory regress when it comes to the necessity of particular facts, a problem to which I return in the final section of this article. For now, I will ignore this problem and focus on the counterexamples Craig presents. Although I shall give these counterexamples names for ease of reference, please note that the names are mine, not Craig's.

Arithmetic: " $2+2=4$ " is a necessary truth, but " $2+2=4$ " is explained by another set of necessary facts namely: the Peano axioms for arithmetic.

Trinitarianism: Under some interpretations of theism, God exists necessarily and God is essentially trinitarian. This implies that, necessarily, a plurality of persons exists, i.e. that "There exists a plurality of persons" is a necessary truth. But this necessary truth is explained by the existence of God.

Temporal Becoming: "No event precedes itself" is a necessary truth about time, but "no event precedes itself" is explained by the necessary truth "Temporal becoming is an essential and objective feature of time" (and it would be absurd to think that the explanation could go in the other direction).

For the time being, we shall ignore Trinitarianism since it closely resembles a counterexample offered by Murphy and it will make more sense to deal with them together. This leaves us with Arithmetic and Temporal Becoming, the first of which involves a logical/mathematical fact and the second of which could be viewed as either an analytical or metaphysical fact. If these examples are true instances of necessary facts being explained by other necessary facts, then they would pose serious problems for the NEP argument. But are they true instances of such explanations? Three observations seem apposite here.

First, neither of the examples is uncontroversial. Craig's purported explanation of the proposition "no event precedes itself" relies on a theory of time that is hotly contested, and the purported explanatory links between that proposition and the proposition about temporal becoming is somewhat sketchy, as we shall see in a 
moment. Similarly, while the claim that " $2+2=4$ " is a necessary fact is likely to garner near-universal assent, the claim that the Peano axioms explain its truth is rather more questionable. Leaving aside the broader issue of whether the Peano axioms actually have any kind of explanatory power (an issue I will address in a moment) there is the problematic fact that having a complete, consistent and self-contained axiomatic underpinning for all mathematical endeavour has been undermined by the Godel proofs. Thus, some concern may be expressed as to whether there is any advance in explanatory understanding provided by the axiomatic approach here at all.

It may be objected that since there are no complete systems of explanation, this demands too much from Craig's counterexamples. As long as he can provide one case in which there is an explanatory bridge from one necessary fact to another, his counterexamples might be deemed successful, whether or not the necessary fact that is doing the explaining is itself appropriately grounded or epistemically secure. But this objection ignores the fact that the incompleteness of explanatory systems is what is at issue here. If the truth of " $2+2=4$ " is grounded in a fundamentally incomplete set of axioms, but that truth is itself more secure than the underlying set of axioms, then one can reasonably question whether there is any explanation at all. ${ }^{22}$ The quest for understanding always terminates somewhere (following NIRP), and what we are seeking is the most metaphysically or logically appropriate termination point. If the Peano axioms do not seem to bring many explanatory advantages, and indeed if they raise more problems than they seem to solve, then arguably there is no need to proceed to them when explaining " $2+2=4$ ". ${ }^{23}$ That fact is grounded enough in and of itself; to explain it by appealing to less certain, less well-grounded facts looks absurd. Perhaps something similar is true of moral facts like "pain is intrinsically bad": trying to ground them in deeper, more metaphysically doubtful facts is dubious if they are more veritistically secure than the allegedly grounding facts. ${ }^{24}$

\footnotetext{
${ }^{22}$ Wittgenstein, L. On Certainty (trans. E. Anscombe) (Oxford: Blackwell, 1979) makes a similar point about Moore's claim to know that he has two hands.

${ }^{23}$ This isn't to say that the quest for such a grounding is always fundamentally misguided. This is something that can only be fully determined after the explanation has been proposed. But as I say below it is doubtful that, given the nature of necessary moral facts, theistic explanations are up to the task.

${ }^{24}$ Pleasants, relying on Wittgenstein, makes this point directly in relation to the ethical injunction against killing and the badness of death. See Pleasants, N. "Wittgenstein, Ethics and Basic Moral Certainty" (2008) 51 Inquiry 241-267
} 
Superficially, this objection may seem to conflate the distinction between epistemology and ontology, which I was so keen to draw earlier on. But that is not the case. In line with what I said at the end of section 2, sometimes epistemic or evidential considerations will provide defeasible evidence for ontological conclusions. So the claim being made here is simply that when a proposition has certainty as part of its essential character, that provides some evidence for the claim that it does not have an explanation, and some evidence for the claim that it is not grounded in less certain facts. ${ }^{25}$ Mathematical facts - and, I submit, some moral facts - are of this sort: they are unlikely to need grounding in less certain facts. Furthermore, there are other characteristics of necessary moral truths that add more such evidence to the mix. This is where my second and third observations about Craig's counterexamples come into play.

The second observation begins by raising a simple question: in each of the cases presented by Craig, what exactly is being explained? Is it the necessary truth of the respective facts that is being explained, or is it just the truth of the facts themselves? In other words, is it the fact " $2+2$ " equals " 4 " that we are trying to explain, or is it the fact that " $2+2$ " necessarily equals " 4 " that we are trying to explain? There is good reason for thinking that it must be the latter: an explanation of a proposition should, ideally, explain all key features of that proposition, and necessity is one of the key features of the propositions under consideration. But this creates certain problems of regress since we are effectively transferring necessity from one fact to another, and not explaining it at all. This observation forms the backbone of Blackburn's dilemma, which is a dilemma about the source of necessity. In the final section of this article, I will argue that this dilemma can be used to support the NEP principle, particularly when it applies to necessary moral facts.

The third observation is this: if we assume, contrary to what I just said, that what is being explained in each of the counterexamples is the truth of the propositions and not their necessity, we must ask: are the facts really being explained? This brings us back to the issue of whether the Peano axioms or the statements about the objective nature of time really have explanatory power. I submit that they do not. When one looks

\footnotetext{
${ }^{25} \mathrm{I}$ am indebted to an anonymous reviewer for encouraging me to make this clarification.
} 
at the Peano axioms or at a claim like "temporal becoming is an essential and objective feature of time", one really only finds more detailed conceptual definitions, analyses or spellings-out of the propositions in question. To suggest that these expanded definitions or conceptualisations have explanatory power seems anachronistic: they simply state more clearly and at greater length what was already contained in the original proposition. To quote from Wielenberg, commenting on the necessary truth that $2+2$ does not equal $5,^{26}$

"It is the essential character of the numbers 2 and 5 , and of the relations addition and identity, that make it the case that necessarily, $2+2$ is not equal to 5 ."

That is to say, everything we need to explain the original necessary proposition is in fact contained in the proposition. To say that the proposition is explained by the properties of the numbers and by the relations of addition and identity (which are simply spelled out in the Peano axioms) is to add nothing in terms of the ontological grounding of mathematical truths. The same seems to be true of the claim that the objectivity of temporal becoming explains why no event precedes itself, except that the former is arguably more opaque than the latter. If this is right, then its not clear that Arithmetic or Temporal Becoming are true counterexamples to NEP since it is not clear that they contain any real explanations.

To underline this point, consider the following counterexample to NEP, which resembles the ones offered by Craig:

Painfulness: "Pain is intrinsically bad" is a necessary moral fact, but this is explained by the fact that pain is a kind of harm and badness is an essential and objective property of harmfulness.

Looking at this counterexample, we have to ask: do the essential and objective properties of harmfulness really explain why pain is intrinsically bad? Or do they simply spell out in more detail what was already contained in the original proposition

\footnotetext{
${ }^{26}$ Wielenberg, E. Value and Virtue in a Godless Universe (Cambridge: Cambridge University Press, 2005), p 51
} 
about pain? I submit that it is the latter. We have merely been provided with a more detailed conceptualisation of pain, which defines it as a form of harm; we have not been shown why it is that certain properties such as harmfulness make a moral difference in the world; we have simply been told that they do. The ontological grounding or informative identification one would expect from an explanation is lacking. ${ }^{27}$

In addition to these three observations, a more general point can be made about Craig's counterexamples. Even if Craig's counterexamples were successful -- that is: even if some necessary truths $d o$ have explanations -- that would at best provide us with a reason to reformulate NEP, not with a reason to reject the notion that necessary moral truths have no explanations. After all, in each of the examples cited by Craig another necessary fact is appealed to and this fact is left unexplained. Perhaps this fact can in turn be explained, but nearly everyone agrees that explanations must terminate somewhere and that the most appropriate termination point will be in some basic, sui generis, self-evidencing facts. Presumably even Craig would accept this, he just happens to argue that God is that fact. So the debate here is primarily about the appropriate stopping-point for explanations of necessary moral facts, not with whether all necessary truths have explanations.

Although Craig and other theists like Murphy may argue that God is the appropriate stopping point for all explanations, there are some good reasons for thinking that moral facts must themselves be basic, sui generis and self-evidencing. Many have argued this point. ${ }^{28}$ In doing so they point to features of moral facts that make it unlikely that they can be explained by another species of fact. Examples of such features would include the apparently unbridgeable logical chasm between is and ought claims; the oft-cited metaphysically queer nature of moral properties; ${ }^{29}$ the problems of propagating error that arise when one attempts to reduce moral facts to non-moral ones,

\footnotetext{
${ }^{27}$ The "informative identification" phrase comes from Murphy, M. "Theism, Atheism and the Explanation of Moral Value" in Garcia and King (eds) Is Goodness without God good Enough? (Rowman \& Littlefield, 2009) and is explicitly accepted by Craig later in the same book at p. 168.

28 cf. Morriston, W. "God and the Ontological Foundation of Morality" (2012) 48 Religious Studies 15-34 and Wielenberg, E. "In Defense of Non-Natural Non-Theistic Metaethics" (2009) 26 Faith and Philosophy 23-41 ${ }^{29}$ Of course, the metaphysically queer nature of moral properties is also cited as a reason for accepting moral nihilism. This may be the correct attitude to take, but if we are accepting that certain moral facts exist, as we are for the purposes of this article, then metaphysical queerness would seem to be a reason for thinking that those moral facts could not be grounded in anything else.
} 
specifically the apparent loss of normativity that this seems to entail; and, most importantly, the fact that the necessity of certain moral truths seems to be an immanent and transparent aspect of the concepts and entities to which they refer, i.e. their necessity is not merely accidental or derivative (a point I return to later). ${ }^{30}$ These features suggest that if moral facts do exist and if they are necessary, then they would not ultimately be capable of being explained by anything external to themselves. In other words, there seem to be good reasons for thinking the following revision of NEP is true:

NEPM: If $\mathrm{X}$ is a necessary moral fact, then $\mathrm{X}$ has no explanation.

This revised principle would allow the necessary-truth objection to theistic metaethics to go through, even if Craig's counterexamples were successful. ${ }^{31}$

\section{2 - Craig's Principle of Explanation}

So much for Craig's counterexamples. What about his attempt to provide an alternative principle of explanation? Craig isn't as explicit in presenting an alternative account of explanation as Murphy is, but he still has something to say about the matter. To understand the principle that Craig offers, we need to engage in a brief divagation into some of his other metaethical theses.

In the course of his defence of theistic metaethics, Craig attempts to dismiss Platonic moral realism. As he does so, he presents something like a principle of explanation that would allow for necessary moral facts to be explained. Platonic moral

\footnotetext{
${ }^{30}$ Mark Schroeder "Realism and Reduction: The Quest for Robustness" (2005) 5(1) Philosophers' Imprint, available at http://philosophersimprint.org/005001/, accessed 18/04/12. Of course, Schroeder thinks it may be possible to reduce some moral facts to facts about individual reasons for action. I take it that this may well be true - and indeed would be inclined to support it myself - but do not discuss it here since it does not support the contrary view being explored in the main body of the article. This is because the normativity of reasons for action is still left as a basic, sui generis feature of reasons for action.

${ }^{31}$ This suggests an important link between the criticisms I mount in this article and more general critiques of the actual metaethical explanation offered by Craig (modified divine command theory). For critiques of this sort, see: Morriston, W. (2012); Wielenberg, E. (2005 and 2009) and Koons, J. "Can God's Goodness Save the Divine Command Theory from Euthyphro?" (2012) 4 European Journal of Philosophy 177-195. All these critiques make similar claims: that the stopping point offered by Craig is implausible because moral facts require no grounding beyond themselves or because any purported theistic explanation tends to run into some revised version of the Euthyphro (i.e. grounding moral truths in theistic facts tends to undermine their necessity). The arguments I make here connect up with those critiques: I am saying that necessary moral truths do not have explanations because those truths have properties that make any purported grounding implausible.
} 
realism -- which can also be termed non-natural non-theistic moral realism ${ }^{32}$-- is essentially the view I just outlined. It claims that moral facts are abstract, basic and sui generis, not capable of being grounded in either natural or theistic facts. Instead, they float free, independent of these other ontological moorings.

Craig holds that this view makes no sense. ${ }^{33}$ As he puts it, to say that moral statuses such as moral values and moral obligations exist in some abstract realm is odd. It makes sense to say that moral values exist as properties of persons; but not as abstract entities. It makes sense to say that moral obligations are owed to persons; but not that they are owed to some abstraction. ${ }^{34}$ Leaving aside some obvious difficulties with these arguments, ${ }^{35}$ what is most interesting for present purposes is the principle of explanation that seems to be motivating them. For Craig, an explanation is something needed when things don't make sense, when there is an oddness to the facts under consideration. That gives us Craig's principle of explanation.

Craig's Principle of Explanation (CPE): Even if X is necessary, if X makes no sense (if $\mathrm{X}$ is metaphysically odd), then $\mathrm{X}$ needs/has an explanation.

There are at least three problems with using the CPE to respond to the necessary-truth objection. First, there is a danger that it renders our quest for explanation beholden to our epistemic needs: just because $\mathrm{X}$ is incomprehensible to us, does not mean that $\mathrm{X}$ must have an explanation. Second, as I pointed out above, the queerness/oddness of moral facts cuts both ways. There seem to be several good reasons for thinking that moral facts are basic and sui generis, and among them is the claim that they are metaphysically queer. If these reasons are correct, then it would be the case that any explanation that reduced moral facts to another set of facts would not make sense, not vice versa. Third, and following on from this, if this non-reducibility of moral facts is consistent with broader arguments about the explanation of necessary truths, then what

\footnotetext{
${ }^{32}$ Wielenberg (2009)

${ }^{33}$ Craig (2008) p. 178: "It is difficult, however, to even comprehend this view."

${ }^{34}$ On each of these claims, see Craig (2008), p. 178.

${ }^{35}$ For example, even in the Platonic view, obligations would still typically be owed to persons and values would still be properties of persons so it's not clear what the problem is, unless one thinks that all abstract properties are metaphysically problematic. Furthermore, the theistic view supported by Craig doesn't seem to solve these problems any better than the non-natural view. See Wielenberg (2009), and Koons (2012) on this point.
} 
initially appeared to cut both ways may in fact cut more decisively against CPE. I try to defend this claim in the final section. Hence I conclude that Craig's attempt to substitute CPE for NIRP and CP, and thereby undermine NEP, is unpersuasive.

\section{Mark Murphy contra NEP}

In this section, I consider Mark Murphy's response to the necessary-truth objection in his recent book God and Moral Law. The response is brief, but densely argued. ${ }^{36}$ Like Craig, Murphy presents a counterexample to NEP and develops an alternative principle of explanation that allows for necessary moral facts to be explained. Unlike Craig, Murphy is rather more explicit in developing this alternative principle. I consider both aspects of Murphy's response in turn.

\section{1 - Murphy's Counterexample}

Murphy only presents one counterexample to NEP: ${ }^{37}$

Created Being: Under some interpretations of theism, God exists necessarily and God is essentially creative. This implies that, necessarily, created being exists, i.e. that "There exists at least one created being" is a necessary truth. But this necessary truth is explained by the existence of God.

The similarities with Craig's Trinitarianism should be readily apparent. Both examples posit that God is a necessary being; both examples point to certain essential properties of God; and both highlight how these essential properties give rise to other necessary facts, the existence of a plurality of persons in the one instance and the existence of created being in the other. Although one can readily concede that, when structured in this manner, the examples sound superficially plausible, when one probes a little deeper this becomes more questionable. Two distinct but related lines of objection arise. The first is concerned with epistemic routes to our knowledge of necessary fact and the qualities of the propositions being explained under those different epistemic routes, and

\footnotetext{
${ }^{36}$ Murphy (2011) pp. 45-49

${ }^{37}$ Murphy (2011) p. 48
} 
the second is concerned with the important differences between factual necessity and metaphysical necessity.

First, consider how in the case of Craig's counterexamples - Arithmetic and Temporal Becoming - the propositions being explained are accepted as necessary independently of their explanations. That is to say, their necessity is part and parcel of what they are. When we look at a proposition like " $2+2=4$ ", it seems impossible for it to have been any other way. The nature of the number " 2 " and the relations of additivity and equality are such that its truth could never be doubted. This would also seem to be true in the case of moral facts - it seems impossible to say that pain is not intrinsically bad or that torturing innocent children for fun is right. ${ }^{38}$

Now note how the situation is reversed in the case of Trinitarianism and Created Being. One only knows that it is necessary for there to be created being or for there to be a plurality of persons, if one already accepts that God is necessary and that God has certain essential properties that give rise to these facts. ${ }^{39}$ If one knows neither of these things, then the fact that more than one person exists or the fact that there is created being, would have no semblance of necessity about it. As Murphy comments: "there is no reason to believe that this state of affairs obtains necessarily except in virtue of that which would, if true, explain it". ${ }^{40}$ In other words, the epistemic route to necessity is reversed between the two sets of cases. In the former cases, necessity is what comes first and is part and parcel of what has to be explained; in the latter, necessity comes after the explanation and is not part of what has to be explained.

But does this really make a difference? Even if there is this disanalogy between the examples, couldn't Trinitarianism and Created Being still provide sound

\footnotetext{
${ }^{38}$ Indeed, the fact that there are necessary/absolute wrongs, which can be known independently of God, is an essential component of Craig's moral argument for the existence of God. See Morriston (2012) for more on this point.

${ }^{39}$ A reviewer objects: what if one received divine revelation of the necessity of the first fact, then later linked that to the necessity of God? My response is twofold. First, if the revelation simply consists in a strong unshakeable belief in the necessity of $\mathrm{P}$ without any link to God (without any revelation of, say, the fact that God caused $\mathrm{P}$ to come into being) then I suggest the subsequent connection to God will seem implausible for reasons stated elsewhere in this article: where P seems to be immanently necessary, to have necessity as part and parcel of its nature, it is highly unlikely that $\mathrm{P}$ has an explanation. Second, if the revelation includes the link to God (e.g. if it is of the sort "I made P necessary") or if the subsequent link to God is causal in nature, I would argue it is addressed by the factual necessity vs. metaphysical necessity argument that I make below.

${ }^{40}$ Murphy (2011), p. 48
} 
counterexamples to NEP? After all, it is an old saw in scientific practice that the context of discovery (i.e. the context in which we become aware of an explanation) is distinct from the context of verification (i.e. the context in which we ascertain the truth of the explanation), and the epistemic problems associated with the former do not necessarily transfer onto the latter. Could the same not be true here, in the sense that our becoming aware of the necessity of plural persons or created being after becoming aware of God's necessity and His essential properties need not weaken the explanatory grip the latter has on the former?

I think the answer has to be "no". For once we change the epistemic route to our knowledge of necessary facts in this manner, many of the properties and characteristics of the facts alter. If there is no good reason for thinking that the fact we are trying to explain is necessary independent of its explanation -- as there isn't in the case of plural persons and created beings -- then there is no immanent or apparent necessity at stake in their explanation. For instance, assuming we knew or believed nothing about God, it would no doubt be possible to explain the existence of particular created beings by pointing to various other (contingent) facts. These other facts could provide satisfactory explanations of particular created beings, ones that seem plausible, well-motivated and successful. That is to say, the explanations could satisfy our intellectual curiosity and provide solid ontological groundings for each of the facts being explained. If, after having provided these explanations, it turns out that other aspects of our worldview suggest that the facts were necessary, are we then forced to cast-off our previous explanations for those facts? I think not; the necessity of those facts is, ironically, a largely derivative side effect of another belief we happen to hold; it is not something that requires an explanation independent of that belief. The pre-existing explanations will suffice to explain why the facts are as they appear to be. This is very different from the case of necessary moral or mathematical truths, where the necessity of those facts is one of the properties that defines them.

This may ring a little hollow. Surely if God causally explains created being, and it can be shown that God is necessarily creative, we have a genuine counterexample on 
our hands $?^{41}$ After all, the explanans (God) and the explanandum (created being) are clearly distinct in this scenario; the causal chain between the two takes care of this. That brings us to the second, and more important, line of objection. This one argues that even still, this is not a true counterexample to the explanation of necessary truths because it conflates factual necessity and metaphysical necessity. The argument rests on the principle that a counterexample showing that a factually necessary proposition has an explanation could be successful without thereby defeating the claim that a metaphysically necessary proposition does not have an explanation. The argument then claims that Trinitarianism and Created Being merely provide examples of factually necessary propositions being explained, and not examples of metaphysically necessary propositions being explained (which is what necessary moral truths seem to be). Both the principle and the claim need to be defended.

Turning to the principle first, as noted earlier, a fact is metaphysically necessary if it is true in every possible world. It is factually necessary if, although it may fail to be true in some possible worlds, in any world in which it is true, it cannot fail to be true. Given these definitions, it seems plausible to suggest that the explanation of a factually necessary proposition could have philosophical implications that differ from the implications arising from the explanation of a metaphysically necessary proposition. Specifically, it seems plausible that the explanation of factually necessary propositions could be accounted for by the fact that such propositions fall under the counterfactual principle of explanation. This principle entails only that truths that could have been otherwise have explanations. Since factually necessary truths could have been otherwise (there are possible worlds in which they fail to hold) they are covered by this principle. Of course, the counterfactual principle of explanation is rejected by Murphy (as we shall see in a moment) but the basis for such rejection would not undermine the point I am making. The principle is rejected on the grounds that it does not cover all cases in which explanations are possible, not on the grounds that it fails to account for those cases in which it applies. All my argument requires is for it to do the latter.

\footnotetext{
${ }^{41} \mathrm{I}$ am indebted to an anonymous reviewer for pressing me on this point.
} 
So we turn then to the question: Is it true that Trinitarianism and Created Being involve factually necessary propositions as opposed to metaphysically necessary ones? I argue that they do because there is no contradiction or implausibility attached to the notion of worlds in which created beings and plural persons are strictly contingent matters. Of course, this is something that theists like Craig and Murphy might strenuously deny. ${ }^{42}$ They might claim that God is a metaphysically necessary being and has creativeness and plurality as part of his essence in every possible world. If this is right, the existence of created beings and plural persons is not merely factually necessary but metaphysically necessary too.

But this counterargument faces two problems. First, the notion that God is a metaphysically necessary being should be approached with at least some trepidation. Certainly, it has seemed possible to many over the years that God might fail to exist in at least one possible world. Second, even if God were a metaphysically necessary being, the notion that he is necessarily plural or necessarily creative seems rather more doubtful. While one can see the attraction of the view that a maximally perfect being exists in all possible worlds, nothing about that maximal perfection entails that created beings or plural persons must exist. Indeed, suggesting that God necessarily creates in every possible world would seem to contradict his having free will. ${ }^{43}$

In conclusion then, neither Trinitarianism nor Created Being are proper counterexamples to NEP. At best, they provide examples of derivative or factually necessary propositions being explained, not metaphysically necessary propositions. The NEP and the NEPM only makes claims about the latter, they refer explicitly to a particular subset of necessary facts that are immanently necessary, i.e. they appear in themselves to be basic and sui generis.

To be fair to him, Murphy is aware that there may be important differences between moral facts and the fact that there is created being. He tries to account for those

\footnotetext{
${ }^{42}$ Craig certainly adopts this view, see Is Goodness without God Good Enough?, p. 170, but as Craig himself notes, Murphy may not adopt this view.

${ }^{43}$ Of course, people have argued that God couldn't possibly be free, but this is a hotly contested point.
} 
differences by developing a principle of explanation that specifically addresses the properties of necessary moral facts. We look at this next.

\section{2 - Murphy's Principle of Explanation}

As explained above, the NEP argument derives its force (in part) from two explanatory principles: NIRP and CP. The first of those principles simply points out that there cannot be an infinite regress of explanations; the second adds to this the claim that explanations are supposed to show us why what need not have been the case is, in fact, the case. Conjunctively, these two principles make a decent case for NEP: NIRP stipulates that there must be some stopping point, CP specifies what this stopping point is (only contingent facts have explanations), and this stopping point rules out the explanation of necessary facts.

Murphy challenges this argument by replacing CP with an alternative explanatory principle. As he puts it:
"The mistake is to suppose that it is essential to explanation to show why what need not be nevertheless is. What is essential to explanation is to show why what is, is; this will, in the case of contingently obtaining states of affairs, involve showing why what need not be is, but it may also be that for some necessarily obtaining states of affairs it is possible to show why what must be is, and even must be. ${ }^{, 44}$

The first sentence of the quoted passage is an explicit rejection of $\mathrm{CP}$. The second sentence appears to offer a replacement principle (let's call it Murphy's Principle of Explanation or MPE for short) of the following sort:

MPE: Whatever is the case has an explanation.

\footnotetext{
${ }^{44}$ Murphy p. 48
} 
Of course, this principle comes dangerously close to emulating (maybe even surpassing) the much-maligned principle of sufficient reason (PSR). But its pretty clear from the rest of what he has to say that Murphy does not intend to endorse anything as strong as MPE: he does not think that every fact has an explanation. Instead, he wishes to limit explanation to a certain sub-species of necessary fact. The following three passages help us to identify the characteristics of this sub-species. The first passage contains his application of his explanatory principle to the case of Created Being; the second tries to show why this carries over to the case of necessary moral facts; and the third passage seems to sum up his views on explanation:

"The reason that there is created being seems to call for explanation, even if one's view has it as a necessary truth, is that there seems to be nothing in the essence of any creature that entails its existence; knowing what the creature is does not tell us why it must exist." 45

"It does not seem to be part of what it is to be pain that it is morally necessary not to inflict it without further reason to do so [reference omitted], nor is it part of what it is to be a harmless child that it is morally necessary that one not aim at that child's death or injury." 46

"Moral facts do not seem to be self-explanatory. Nor again do they seem to be brute: to think that they are necessary and brute generates puzzles rather than solving them. So we should expect that moral facts, all of them, are explanation eligible." $" 47$

Murphy never specifies exactly what the "puzzles" alluded to in the third passage are. He may have in mind here something similar to Craig: that brute moral facts are metaphysically queer. If his view is like that of Craig, then my response is above. If it is something else, then I leave it to him to specify exactly what it is.

\footnotetext{
${ }^{45}$ Murphy (2011), p 48, italics original

${ }^{46}$ Murphy (2011), p. 49, italics original

${ }^{47}$ Murphy (2011), p. 49
} 
Leaving that issue to the side, and extrapolating from the three passages, we can construct the following revised version of Murphy's explanatory principle:

MPE*: For any fact $X, X$ is explanation-eligible if (a) $X$ is contingent or (b) $X$ is necessary but does not appear to have necessity as part of its nature, to be selfexplanatory, or to be brute.

If MPE* is combined with NIRP we would have reason to reject NEP. But the more important question here is whether we would also have reason to reject NEPM. Again, I think the answer has to be "no". Murphy clearly attempts to refute NEPM by claiming, for example, that "it does not seem to be part of what it is to be pain that it is morally necessary not to inflict it without further reason to do so" ${ }^{, 48}$ but this refutation will ring hollow to most proponents of the view that moral facts are necessary. They will simply reply that of course it is part of and parcel of what it is to be pain that one should not inflict it without further reason. That pain automatically has a moral disvalue attached to it seems be a metaphysically essential aspect of what pain is (or, alternatively, that it is a conceptually essential aspect of what pain is). The same would hold for the torture case. Since torture involves the application of severe pain, since pain is intrinsically bad, and since the innocence of the victim rules out any overriding reasons for engaging in torture, that claim is necessarily true: it is part of the essence of torture and innocence that the torture of the innocent is wrong. To the person who suggests "but imagine a world in which pain was good...or torturing the innocent is permissible" proponents of the necessity of those truths will rightly respond with quizzical looks and raised eyebrows. Such a world would be a nonsense, much like a world in which the fallacy of affirming the consequent was not a fallacy. ${ }^{49}$

In other words, it is possible to accept MPE* and still hold to the view that necessary moral facts do not have an explanation. Murphy's substitution of an alternative explanatory principle for $\mathrm{CP}$ does nothing to undercut this view since it still

\footnotetext{
${ }^{48}$ Murphy p. 49

${ }^{49}$ My colleague Felipe Leon (personal correspondence) points out to me that "One might also appeal to the principle of credulity or phenomenal conservatism here as well, arguing that such propositions just seem to one to be necessary, in which case one has prima facie evidence that they are necessary."
} 
calls for some explanatory stopping points and does not successfully show that moral facts are not among those stopping points.

\section{A General Defence of NEP and NEPM}

To this point, I have argued against Craig and Murphy's responses to those who claim that necessary moral facts do not have an explanation. This is to provide a negative defence of that position. In this final section, I want to go one step further and provide one positive-ish argument in its favour. The argument builds upon some of the ideas developed over the previous sections, but also introduces one new idea:

Blackburn's Dilemma.

Blackburn's Dilemma poses a problem for any attempt to explain what it is that makes necessary truths necessarily true. In other words, it poses a problem for any attempt to explain the source of necessity. The dilemma itself is easily stated: ${ }^{50}$

Blackburn's Dilemma: Either the necessity of a necessary truth is to be explained by a contingent truth or it is to be explained by another necessary truth. If the necessity of a necessary truth is explained by a contingent truth, then that contingent truth could have been otherwise and hence the necessary truth need not have been necessary (contingency horn). Therefore, the necessity of a necessary truth cannot be explained by a contingent truth. But if a necessary truth is explained by another necessary truth, then we have not explained its necessity, we have simply transferred its necessity elsewhere and started off on a regress of necessary truths (necessity horn).

Although Blackburn himself uses the dilemma to motivate a quasi-realist account of necessity, this can be ignored for present purposes. The key implication for us is that there can be no illuminating explanation (ontologically speaking) of the necessity of necessary truths. As a result, necessary truths must be viewed as either (a) non-existent, i.e. there are no necessary truths or (b) sui generis, brute inexplicable facts. Since we are

\footnotetext{
${ }^{50}$ Blackburn, Simon "Morals and Modals" in Blackburn, S. Essays in Quasi-Realism (Oxford: OUP, 1993)
} 
assuming that there are at least some necessary truths, we must accept the second of those options, not the first.

If Blackburn's Dilemma is correct, then it could be recruited as part of a generalised defence of NEP. This would work in the following manner:

(10) If it is not possible to explain necessary truths, then NEP is true.

(11) In order to explain any necessary truth we must not only explain why it is true but also why it is necessarily true.

(12) It is not possible to explain the necessity of necessary truths (because of Blackburn's Dilemma).

(13) Therefore, it is not possible to explain necessary truths (from 11 and 12).

(14) Therefore, NEP is true (from 10 and 13).

There are, however, certain problems with this attempted defence of NEP. Chief among them is the fact that there are formal problems with the traditional formulation of Blackburn's Dilemma. If these problems are fatal, there is reason to reject premise (12). Hanks ${ }^{51}$ has argued, for example, that the contingency horn of the dilemma might be deemed to both: (a) rely, in a question-begging manner, on the characteristic axiom of S4 modal logic; ${ }^{52}$ and (b) rely on certain principles of explanation that do not apply to causal explanations. However, in the same article, Hanks shows that it is possible to reformulate the dilemma so that it does not rely on the characteristic axiom of S4 so the first problem can be overcome. Likewise, Hanks argues that explanations of necessity are more likely to be reductive or grounding-style explanations, not causal explanations. Hence, the second problem can also be avoided.

Other problems arise for the necessity horn of the dilemma. Hale, ${ }^{53}$ for instance, has argued that the regress only arises if explanations of necessity are transmission

\footnotetext{
${ }^{51}$ Hanks, P "A Dilemma about Necessity" (2008) Erkenntis 68: 129-148

${ }^{52}$ Which states: "it is necessary that P implies that it is necessarily necessary that P."

${ }^{53}$ Hale, R "The Source of Necessity" (2002) in Tomberlin, J. (ed) Philosophical Perspectives 16: 299-320.
} 
explanations, and not if they are non-transmission explanations. A transmission explanation is one that appeals not just to the truth of some necessary proposition but to the necessity of that proposition as well; a non-transmission explanation is one that only appeals to the truth of a necessary proposition. Hale further argues that at least some explanations of necessity can be non-transmission explanations. However, once again, Hanks has argued that this is wrong: all putative non-transmission explanations are really transmission explanations in disguise. There is a good reason for this. Assume that the necessity of proposition $\mathrm{P}$ is explained by citing another necessary proposition $\mathrm{R}$, but that the necessity of $\mathrm{R}$ is left out of the explanation. In that case, it would be left open whether R is necessary or contingent. But that would mean that it would also be left open whether P was necessary or contingent. Hence, the necessity of P would be left unaccounted for. This could not be a satisfactory explanation of necessity. So, once again, Blackburn's dilemma seems to survive.

Admittedly, this isn't anything like a complete defence of the dilemma. But, in chasing down some of the dialectical paths, as I have just done, I think it is plausible to infer that the dilemma can indeed be formulated in such a way that the formal problems can be successfully avoided. Thus, I take it that premise (12) of the above argument can be defended.

That leaves us with premise (11) as the other potentially problematic component of this defence of NEP. This premise raises the obvious question: why do we have to explain the necessity of necessary truths in addition to their truth? One supporting argument here, discussed above in relation to Craig's counterexamples, is that a successful explanation of a proposition should explain all the distinguishing features of that proposition. So if one of the features of the proposition is that it is necessarily true, that feature should be explained. But that attempted defence of premise (11) falls a little flat in light of the Trinitarianism and Created Being counterexamples. Both of those examples used propositions that did not seem to be necessary, but then linked them to another fact in such a way that they became necessary. Thus, in Created Being the fact that there was created being turned out to be necessary because of the essential properties of God. The success of this kind of explanation does not seem to depend in 
any way on whether it provides an explanation of the necessity of the proposition "there exists created being", all that matters is that it explains why created beings exist. Thus, we seem to have at least one example of a necessary proposition whose necessity does not need to be explained.

Of course, I have already challenged the view that these counterexamples actually cover cases of metaphysically necessary truths and my challenge could be taken to disrupt this objection to premise (11). And there is also the difficulty that once it becomes known that a fact is necessary, the transmission problem will rear its head. However, neither of those challenges are needed here. Instead, it is sufficient to restate the point I made above: even if there are some necessary facts for which (11) does not hold true, necessary moral facts are not like this. Necessary moral facts are propositions whose necessity seems to be bound up in what they are; is immanent in the concepts and entities to which they refer. They are not merely incidental side effects of other beliefs we happen to have. When we consider a proposition like "Pain is intrinsically bad" it looks like this proposition couldn't fail to be true, that it is part of what it means to be a pain is that it is necessarily bad, bad in all possible worlds. Thus, when we look for an explanation of that proposition, we will have to include an explanation of its necessity, not just its truth.

In other words, premise (11) can be reformulated so that it only concerns necessary moral truths:

$\left(11^{*}\right)$ In order to explain any necessary moral truth we must not only explain why it is true, we must also explain why it is necessarily true.

The remainder of the argument can be reformulated to take into account the fact that it is now restricted to necessary moral truths, which is simply to say that the general defence of NEP outlined above can work a fortiori as a specific defence of NEPM.

\section{Conclusion}


In conclusion, the responses that Craig and Murphy present to the necessary-truth objection to theistic metaethics are problematic for at least three reasons. First, the counterexamples they present are flawed. Properly understood, the counterexamples do not really undercut the general proposition that necessary facts do not have explanations. Furthermore, even if they did undercut that general proposition they would not undercut the more specific proposition that necessary moral facts do not have explanations. Second, the alternative explanatory principles that they introduce to explain moral facts are either improperly motivated (in the case of Craig) or simply question-begging (in the case of Murphy). Third, and finally, it is possible to provide a general positive defence of the necessary truth objection based on a revised form of Blackburn's Dilemma.

Acknowledgments: The author would like to thank Felipe Leon, Justin Schieber, and four anonymous reviewers for helpful feedback and comments on earlier drafts of this paper.

\section{Bibliography}

Blackburn, Simon "Morals and Modals" in Blackburn, S. Essays in Quasi-Realism (Oxford: OUP, 1993)

Cameron, R. “The Grounds of Necessity” (2010) 5 Philosophy Compass 348-358

Craig, William Lane Reasonable Faith: Christian Truth and Apologetics $\left(3^{\text {rd }}\right.$ Edn, Wheaton, IL: Crossway, 2008)

Craig, William Lane "A Reply to Objections" in Wallace, S. (ed) Does God Exist? The Craig-Flew Debate (Burlington, VT: Ashgate Publishing, 2003)

Craig, William Lane "This Most Gruesome of Guests" in Garcia, Robert and King, Nathan (eds) Is Goodness without God Good Enough? (New York: Rowman and Littlefield, 2009) 
Craig "The Indispensability of Theological Metaethical Foundations for Morality" (1997) 5 Foundations 9-12 available at http://www.leaderu.com/offices/billcraig/docs/meta-eth.html (accessed 4/09/12)

Hanks, Peter “A Dilemma about Necessity” (2008) 68 Erkenntis 129-148

Hale, Bob "The Source Of Necessity" (2002) 36 Noûs 299-319. doi: 10.1111/14680068.36.s 16.11

Koons, J. "Can God's Goodness Save the Divine Command Theory from Euthyphro?" (2012) 4 European Journal of Philosophy 177-195

Lipton, Peter "What Good is an Explanation?" in Cornwall, J. Understanding Explanation (Oxford: Oxford University Press, 2004)

Morris, T. \& Menzel, C. “Aboslute Creation” (1986) 23 American Philosophical Quarterly 353-362

Morriston, Wes "God and the Ontological Foundation of Morality" (2012) 48 Religious Studies 15-34

Murphy, Mark God and Moral Law (Oxford: OUP, 2011)

Murphy, Mark "Theism, Atheism and the Explanation of Moral Value" in Garcia, Robert and King, Nathan (eds) Is Goodness without God Good Enough? (New York: Rowman and Littlefield, 2009)

Plantinga, A. "Naturalism, Theism, Obligation and Supervenience" (2010) 27 Faith and Philosophy 247 - 272

Philipse, H. God in the Age of Science? a Critique of Religious Reason (Oxford: OUP, 2012)

Pleasants, N. "Wittgenstein, Ethics and Basic Moral Certainty" (2008) 51 Inquiry 241267

Rahimi, S. "Swinburne on the Euthyphro Dilemma: Can Supervenience Save Him?" (2008) 13 Forum Philosophicum 17-29 
Schroeder, Mark "Realism and Reduction: The Quest for Robustness" (2005) 5(1)

Philosophers' Imprint, available at http://philosophersimprint.org/005001/, accessed $18 / 04 / 12$

Wielenberg, Erik Value and Virtue in a Godless Universe (Cambridge: Cambridge University Press, 2005)

Wielenberg, Erik “In Defence of Non-Natural Non-Theistic Moral Realism” (2009) 26 Faith and Philosophy 23-41

Wittgenstein, L. On Certainty (trans. E. Anscombe and G. H. von Wright) (Oxford: Blackwell, 1979) 